\title{
Pemetaan Dan Analisis Maharah Mata Pelajaran Sejarah Kebudayaan Islam (SKI) Jenjang SMA dan MA (Permendikbud No. 24 Tahun 2016 dan KMA No. 165 Tahun 2014 )
}

\author{
Noorrela Ariyunita \\ Program Magister, Konsentrasi Pendidikan Islam, UIN Sunan kalijaga Yogyakarta \\ Email : noorrelaa@gmail.com \\ Anida Rahmaini \\ Program Magister, Konsentrasi Pendidikan Islam, UIN Sunan kalijaga Yogyakarta \\ Email : annidarahma94@gmail.com
}

\begin{abstract}
The history of Islamic culture is a subject that discusses, studies and tells the history or events of the past about islamic culture. This research was conducted to formulate and analyze maharoh/ skill in subjects Islamic history, mapped based on Permendikbud no. 24 of 2016 and KMA no. 165 2014 year. The research maharoh of Islamic history is done at high school level (SMA / MA). The maharoh analysis is mapped from the essential competency and basic competency on the permendikbud and KMA of islamic history. The purpose of this research is to find the lesson of islamic history that must be mastered by learners on the subjects of islamic history. Based on the analysis of maharah on Permendikbud no. 24 of 2016 year and KMA no. 1652014 year of class X, XI and XII can be concluded that from 11 frequently appearing maharah is: believe, understand, take ibrah, associate, imitate, implements, explain, retell, live, vivify. It can be deduced that the scholarship that is the basic of islamic history skill is the academy to live the sphere of spiritual attitude, to model the social aspect, to reconstruct the realm of knowledge, and to retell the skill domain.
\end{abstract}

Keywords: Maharoh/skill, Islamic Story, School, Islamic School

\begin{abstract}
Abstrak
Sejarah kebudayaan Islam atau SKI adalah mata pelajaran yang membahas, mempelajari dan menceritakan sejarah-sejarah atau kejadian-kejadian pada masa lampau tentang kebudayaan Islam. Penelitian ini dilakukan untuk merumuskan dan menganalisis maharoh/kemahiran pada mata pelajaran SKI, yang dipetakan berdasarkan Permendikbud No. 24 Tahun 2016 dan KMA No. 165 Tahun 2014. penelitian maharoh SKI ini dilakukan pada jenjang sekolah menengah menengah atas (SMA/MA). Analisis maharoh tersebut dipetakan dari KI dan KD yang terdapat dalam permendikbud dan KMA mapel SKI. Tujuan penelitan ini adalah untuk menemukan maharah pelajaran SK yang harus dikuasai peserta didik pada mata pelajaran SKI. Berdasaran analisis terhadap maharah dalam Permendikbud No. 24 Tahun 2016 dan KMA No. 165 Tahun 2014 dari kelas X, XI dan XII dapat disimpulkan bahwa dari 11 maharah yang sering muncul yaitu: meyakini, memahami, mengambil ibrah, mengaitkan, meneladani, mengimplementasikan, menjelaskan, menceritakan kembali, menghayati, menghayati. Dapat disimpulkan maharah yang menjadi dasar kemahiran SKI adalah maharah menghayati untuk ranah sikap spiritual, maharah meneladani untuk ranah sikap sosial, merekonstruksi untuk ranah pengetahuan, dan menceritakan kembali untuk ranah keterampilan.
\end{abstract}

Kata Kunci : Maharoh/kemahiran, SKI, Sekolah, Madrasah. 


\section{PENDAHULUAN}

Islam diketahui memiliki karakteristik yang khas di bandingkan dengan agama-agama yang datang sebelumnya. Di era globalisasi ini, banyak masyarakat dan khususnya bagi para pelajar yang acuh tak acuh dengan sejarah Negara, apalagi sejarah paradaban islam. Dewasa ini mereka hanya memandang sejarah sebagai dongeng yang membosankan untuk di dengar. Padahal, sejarah, apalagi sejarah peradaban islam sangat penting bagi kita semua. Di zaman yang serba canggih seperti sekarang ini, kreatifitas guru sangat dituntut dalam mengembangkan pembelajaran agar tercapainya tujuan pembelajaran tersebut. Kreatifitas dan inovasi guru dalam mengelola kelas sehingga pembelajaran akan menghadirkan suasana yang nyaman dan kondusif adalah hal yang harus diutamakan. Terlebih ketika kita melihat perkembangan model pembelajaran yang tidak menjadikan guru sebagai pusat pembelajaran atau teacher centre.

Berangkat dari masalah di atas, maka peneliti tertarik untuk merumuskan maharoh/ kemahiran pada mata pelajaran SKI, yang kemudian dipetakan berdasarkan Permendikbud No. 24 Tahun 2016 dan KMA No. 165 Tahun 2014. Tujuan dari penelitian ini adalah agar pelajaran SKI menjadi terpetakan kemahirannya dan guru dapat mengetahui kemahiran apa saja yang harus dikuasai peserta didik pada setiap jenjangnya serta dapat menambah pengetahuan kita sebagai pendidik dan menjadi acuan untuk mengembangkan materi pembelajaran kepada peserta didik. Oleh karena itu dirasa penting dan menarik untuk mengkaji terkait Analisis Pemetaan Kemahiran Mata Pelajaran SKI di Sekolah Dan Madrasah berdasarkan pada Permendikbud No. 24 Tahun 2016 dan KMA No. 165 Tahun 2014.

\section{METODE PENELITIAN}

Penelitian ini menggunakan pendekatan kualitatif dengan metode studi kepustakaan. Obyek kajiannya adalah Permendikbud No. 24 Tahun 2016 dan KMA No. 165 Tahun 2014 yang ditinjau dari kemahiran yang ada pada kompetensi dasar dalam pembelajaran SKI. Analisis data dilakukan dengan mengkaji substansi kebijakan dari Peraturan Menteri Pendidikan dan Kebudayaan dan Keputusan Menteri Agama dengan menggunakan kompetensi dasarnya. Dengan demikian, penelitian ini dapat menemukan kemahiran atau maharoh yang harus dikuasai siswa SMA dan MA baik kelas sepuluh, sebelas maupun kelas dua belas dalam kebijakan pemerintah yang tercantum pada Permendikbud No. 24 Tahun 2016 dan KMA No. 165 Tahun 2014

\section{HASIL DAN PEMBAHASAN}

Kata sejarah berasal dari bahasa Arab, yaitu kata Syajarah dan Syajara. Syajarah artinya pohon, sesuatu yang mempunyai akar, batang, dahan, ranting, daun, bunga, dan buah. ${ }^{1}$ Semua peristiwa baik yang menyangkut pemikiran, politik, ekonomi, teknologi, dan seni dalam sejarah Islam disebut sebagai kebudayaan. Jadi kebudayaan ini adalah hasil karya, rasa, dan cipta orang-orang muslim. ${ }^{2}$ Sedangkan kata Islam menandakan bahwa kebudayaan dan rujukan sumber nilai tersebut dihasilkan oleh orang-orang Islam. Ini juga berarti bahwa kebudayaan Islam adalah hasil karya, cipta, dan rasa manusia yang menafsirkan agamanya dari waktu ke waktu. SKI sama dengan sejarah kebudayaan lain pada umunya, yaitu bersifat dinamis. Perbedaannya terletak pada sumber nilainya. ${ }^{3}$

Akar kata lain dari sejarah adalah Syajara. Ini adalah kata dari bahasa Arab yang berarti perselisihan, pertentangan, pergulatan, atau perlawanan. Dari makna etimologis ini, bisa diperoleh makna terminologis sejarah yang berarti berita atau cerita yan menggambarkan perlawanan atau kelompok dengan kelompok lainnya atau satu gagasan dengan gagasan lainnya yang terjadi dalam satu tempat dan waktu tertentu. Dari segi terminologis, sejarah berarti

${ }^{1}$ Departemen Agama RI, Pembelajaran Sejarah Kebudayaan Islam, (Jakarta: Direktorat Jenderal Pendidikan Islam, 2009), hlm. 3.

${ }^{2}$ Ibid., hlm. 4.

${ }^{3}$ Ibid., hlm. 4. 
ilmu yang mempelajari dan menerjemahkan informasi dari laporan dan catatan yang dibuat oleh orang perorang, keluarga dan komunitas tertentu. Pengetahuan mengenai sejarah melingkupi pengetahuan akan kejadiankejadian yang sudah berlalu serta pengetahuan akan cara berpikir sejarah (historis). ${ }^{4}$

Pendapat lain mengatakan bahwa sejarah dari makna etimologis berarti perselisihan, pergulatan, atau pertentangan. Secara terminologis sejarah adalah berita atau cerita yang menggambarkan perlawanan satu kelompok dengan kelompok yang lainnya atau satu gagasan dengan gagasan lainnya yang terjadi dalam satu tempat dan waktu tertentu. ${ }^{5}$ Sedangkan menurut Imam Barnadib yang dimaksud kebudayaan adalah sebagai hasil budi daya manusia dalam berbagai bentuk dan sepanjang sejarah sebagai milik manusia yang tidak beku, melainkan selalu berkembang dan berubah. ${ }^{6}$

Sejarah kebudayaan Islam merupakan ilmu pendidikan Islam, karena mengandung nilainilai Islam yang dapat menjadi contoh ataupun suri tauladan bagi umat Islam khusunya, dan umat manusia pada umumnya. Ilmu pendidikan Islam adalah ilmu yang mengkaji pandangan Islam tentang pendidikan dengan menafsirkan nilai-nilai Illahi dan mengkumunikasikan secara timbal balik dengan fenomena dalam situasi pendidikan. $^{7}$

Jadi dapat dipahami bahwa sejarah kebudaayan Islam (SKI) adalah ilmu yang membahas tentang peristiwa di masa lampau baik yang menyangkut pemikiran, politik, ekonomi, teknologi, dan seni dalam sejarah Islam sebagai hasil karya, cipta, dan rasa manusia yang menafsirkan agamanya dari waktu ke waktu.

${ }^{4}$ bid., hlm. 5 .

${ }^{5}$ M. Basyirudin, Media Pembelajaran, (Jakarta: Ciputat Press, 2002), hlm. 47

${ }^{6}$ Imam Barnadib, Filsafat Pendidikan, (Yogyakarta: FIP IKIP 1987), hlm. 24.

${ }^{7}$ Abdurrachman, dkk, Paradigma Pendidikan Islam, (Yogyakarta: Pustaka Pelajar, 2001), hlm. 25.
Pembelajaran SKI belum memiliki indikator ketercapaian yang jelas seperti pembelajaran Bahasa Arab dan bahasa Inggris. Bahasa Arab memiliki 4 indikator kemampuan dasar yang digunakan untuk mengukur kompetensi siswa. Dalam pelajaran Bahasa Arab terdapat empat kemahiran dasar yang saling berkaitan satu sama lain yang disebut dengan maharah.

Sedangkan kata Maharah secara harfiah

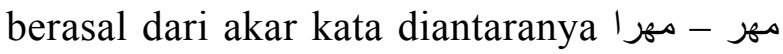
-yang berarti pandai atau mahir. ${ }^{8}$ Makasud dari mahir disini adalah memiliki kemampuan atau skill terhadap suatu hal. Para pakar bahasa telah bersepakat bahwa ada empat kompetensi dasar yang harus dikuasai oleh siswa dan diajarkan di sekolah, diantaranya adalah (1) Maharah kitabah (menulis) yaitu kemampuan dalam mendeskripsikan atau mengungkapkan isi pikiran, mulai dari aspek yang paling sederhana, seperti menulis kata-kata, sampai pada aspek yang kompleks seperti mengarang. ${ }^{9}(2)$ Maharah istima' (menyimak) yaitu kemampuan seseorang dalam mendengarkan dan memahami kata atau kalimat yang diujarkan oleh mitra bicara dan media tertentu, (3) Maharah kalam (berbicara), yaitu kemampuan menungkapkan bunyi-bunyi artikulasi atau kata-kata untuk mengekspresikan pikiran berupa ide, pendapat, keinginan, atau perasaan kepada mitra bicara. ${ }^{10}$ (4) Maharah Qira'ah (Membaca) yaitu proses komunikasi antara pembaca dengan penulis melalui teks yang ditulisnya. ${ }^{11}$ Begitu pula pelajaran Bahasa Inggris memiliki empat keterampilan dasar yang harus diajarkan kepada siswa agar siswa dapat menguasai bahasa inggris, yaitu listening, speaking, reading dan writing. Ke-empat

${ }^{8}$ Ahmad Warson Munawir, Kamus Al Munawir Arab-Indonesia Terlengkap, (Surabaya: Pustaka Progresif, 1997). Hlm. 1363

${ }^{9}$ Acep Hermawan, Metodologi Pembelajaran Bahasa Arab, (Bandung: Remaja Rosdakarya, 2011) Hlm. 1511

${ }^{10} \mathrm{Ibid}, \mathrm{Hlm} .135$

${ }^{11}$ Hendri Guntur Tarigan, Membaca Sebagai Suatu Keterampilan Berbahasa, (Bandung: Angkasa, 1994), HIm. 15 
keterampilan tersebut harus diajarkan kepada siswa supaya siswa memiliki kemampuan dalam menggunakan bahasa baik secara aktif maupun pasif.

Dengan ditetapkannya maharah atau kecakapan dasar yang harus diterapkan dalam pembelajaran akan mempermudah siswa dan guru dalam melaksanakan proses pembelajaran. Guru juga akan lebih mudah untuk mengidentifikasi kecakapan dan materi yang sudah dikuasai atau belum dipahami oleh siswa. Sayangnya, dalam rumpun mata pelajaran PAI belum ditemukan maharah atau kecakapan dasar yang harus dikuasai oleh siswa, sehingga pembelajaran yang dilaksanakan kurang memiliki acuan yang kuat. Salah satu pelajaran PAI yang belum memiliki acuan dasar maharah adalah pelajaran SKI yang sebagian besar materinya adalah tentang sejarah. Guru memiliki kesulitan untuk mengajarkan SKI karena harus menyajikan pelajaran dengan cerita dan tanpa memiliki patokan khusus yang ditekankan kepada siswa. Untuk itu penilitian ini dilakukan untuk mengetahui kemahiran dasar yang harus dikuasai siswa dalam pembelajaran SKI.

\section{Rumusan Kemahiran Mata Pelajaran SKI di SMA dan MA}

Berikut ini merupakan maharah mata Pelajaran SKI yang di ambil dari kompetensi dasar (KD) dalam Permendikbud No. 24 Tahun 2016 dan KMA No. 165 Tahun 2014 yang diurutkan sesuai tingkatannya:

1) Meyakini

2) Meneladani

3) Memahami

4) Menceritakan kembali

5) Mengambil ibrah

6) Mengimplementasikan

7) Menghayati

8) Menjelaskan

9) Mengidentifikasi

10) Menghafalkan

11) Mengaitkan

Maharah tersebut terpetakan dalam empat kompetensi inti (KI) sebagai berikut:
Tabel 1. Maharoh yang terpetakan dalam 4 kompetensi

\begin{tabular}{cc}
\hline KI 1 SIKAP SPIRITUAL & KI 2 SIKAP SOSIAL \\
\hline Meyakini & Meneladani \\
Menghayati & $\begin{array}{c}\text { Mengimplementasikan } \\
\text { Mengambil Ibrah }\end{array}$ \\
\hline KI 3 PENGETAHUAN & KI 4 KETERAMPILAN \\
\hline Memahami & \\
Menjelaskan & Menceritakan kembali \\
Mengidentifikasikan & Menghafalkan \\
Mengaitkan & \\
\hline
\end{tabular}

Yang selanjutnya rumusan maharah di atas digunakan sebagai pisau analisis guna mengetahui penyebaran maharah yang terdapat dalam kompetensi dasar (KD) pada Permendikbud No. 24 Tahun 2016 dan KMA No. 165 Tahun 2014.

\section{Sebaran Maharah dalam Permendikbud} No. 24 Tahun 2016 dan KMA No. 165 Tahun 2014.

\section{Kelas X SMA dan MA}

Tabel 2. Kelas X Permendikbud No. 24 Tahun 2016

\begin{tabular}{lcccc}
\hline \multirow{2}{*}{\multicolumn{1}{c}{ Maharoh SMA }} & \multicolumn{3}{c}{ KD (Kompetensi Dasar) } \\
\cline { 2 - 4 } & KI 1 & KI 2 & KI 3 & KI 4 \\
\hline Meyakini & 2 & & & \\
Meneladani & & & & \\
Memahami & & & 2 & \\
Menceritkan kembali & & & & \\
Mengambil Ibrah & & 2 & & \\
Mengimplementasikan & & & & \\
Menghayati & & & & \\
Menjelaskan & & & & \\
Mengidentifikasi & & & & \\
Menghafalkan & & & & 2 \\
Mengaitkan & & & \\
\hline
\end{tabular}

Pada tabel 2 dan 3, dapat diketahui bahwa maharah tingkat SMA dan MA kelas X menunjukkan kompetensi dasar pada KI 1 lebih menekankan pada maharah meyakini, megambil ibrah dan menghayati. Kompetensi dasar pada KI 2 menekankan pada kmaharah meneladani, mengambil ibrah dan mengimplementasikan. Sedangkan Kompetensi dasar pada KI 3 menekankan pada maharah memahami, menjelaskan, mengidentifikasi dan mengkaitkan. 
Tabel 3. Kelas X KMA No. 165 Tahun 2014.

\begin{tabular}{lcccc}
\hline \multirow{2}{*}{ Maharoh MA } & \multicolumn{3}{c}{ KD (Kompetensi Dasar) } \\
\cline { 2 - 5 } & KI 1 & KI 2 & KI 3 & KI 4 \\
\hline Meyakini & 2 & & & \\
Meneladani & & 6 & 3 & \\
$\begin{array}{l}\text { Memahami } \\
\text { Menceritkan kembali }\end{array}$ & & & & 7 \\
$\begin{array}{l}\text { Mengambil Ibrah } \\
\text { Mengimplementasikan }\end{array}$ & 5 & & & \\
Menghayati & 5 & 7 & & 2 \\
Menjelaskan & & & 11 & \\
Mengidentifikasi & & & 4 & \\
Menghafalkan & & & & \\
Mengaitkan & & & 2 & \\
\hline
\end{tabular}

Sedangkan pada kompetensi dasar pada KI 4 menekankan pada maharah menceritakan kembali, mengimplementasi dan mengkaitkan. Dari tabel diatas dapat ditarik kesimpulan bahwa ada 4 maharah yang sering muncul dalam kompetensi dasar kelas X SMA, yaitu maharah meyakini, memahami, mengambil ibrah dan mengaitkan. Adapun dalam koompetensi dasar (KD) kelas X MA maharah yang sering muncul adalah meneladani, mengimplementasikan, menjelaskan, menceritakan kembali.

\section{Kelas XI SMA dan MA}

Tabel 4. Kelas XI Permendikbud No. 24 Tahun 2016

\begin{tabular}{|c|c|c|c|c|}
\hline \multirow{2}{*}{ Maharoh SMA } & \multicolumn{4}{|c|}{ KD (Kompetensi Dasar) } \\
\hline & KI 1 & KI 2 & KI 3 & KI 4 \\
\hline Meyakini & 1 & & & \\
\hline Meneladani & & & & \\
\hline Memahami & & & 2 & \\
\hline Menceritkan kembali & & & & \\
\hline Mengambil Ibrah & & & & \\
\hline Mengimplementasikan & & 2 & & \\
\hline Menghayati & 1 & & & \\
\hline Menjelaskan & & & & 2 \\
\hline Mengidentifikasi & & & & \\
\hline Menghafalkan & & & & \\
\hline Mengaitkan & & & & 1 \\
\hline
\end{tabular}

Pada tabel 4 dan 5, dapat diketahui bahwa maharah tingkat SMA dan MA kelas XI menunjukkan kompetensi dasar pada KI 1 lebih menekankan pada kemahiran meyakini, menghayati, menceritakan kembali dan
Tabel 5. Kelas XI KMA No. 165 Tahun 2014.

\begin{tabular}{lcccc}
\hline \multirow{2}{*}{\multicolumn{1}{c}{ Maharoh MA }} & \multicolumn{4}{c}{ KD (Kompetensi Dasar) } \\
\cline { 2 - 5 } & KI 1 & KI 2 & KI 3 & KI 4 \\
\hline Meyakini & 2 & & & \\
Meneladani & & 4 & & \\
Memahami & & & 3 & \\
Menceritkan kembali & 3 & & & 4 \\
Mengambil Ibrah & 1 & & & 3 \\
Mengimplementasikan & & 8 & & 3 \\
Menghayati & 5 & & & \\
Menjelaskan & & & 16 & \\
Mengidentifikasi & & & 3 & \\
Menghafalkan & & & & \\
Mengaitkan & & & 2 &
\end{tabular}

mengambil ibrah. Kompetensi dasar pada KI 2 menekankan pada kemahiran meneladani dan mengimplementasikan. Sedangkan Kompetensi dasar pada KI 3 menekankan pada kemahiran memahami, menjelaskan, mengidentifikasi dan mengkaitkan. Sedangkan pada kompetensi dasar pada KI 4 menekankan pada kemahiran menceritakan kembali, menjelaskan, mengimplementasi dan menceritakan kembali. Dari tabel diatas dapat ditarik kesimpulan bahwa ada 3 maharah yang sering muncul dalam kompetensi dasar kelas XI SMA, yaitu maharah memahami, mengimplementasikan dan menjelaskan. Adapun dalam koompetensi dasar (KD) kelas XI MA maharah yang sering muncul adalah menghayati, meneladani mengimplementasi dan menjelaskan.

\section{Kelas XII SMA / MA}

Tabel 6. Kelas XII Permendikbud No. 24 Tahun 2016

\begin{tabular}{|c|c|c|c|c|}
\hline \multirow{2}{*}{ Maharoh SMA } & \multicolumn{4}{|c|}{ KD (Kompetensi Dasar) } \\
\hline & KI 1 & KI 2 & KI 3 & KI 4 \\
\hline Meyakini & 4 & & & \\
\hline Meneladani & & & & \\
\hline Memahami & & & 4 & \\
\hline Menceritkan kembali & & & & \\
\hline Mengambil Ibrah & & 2 & & \\
\hline Mengimplementasikan & & 2 & & \\
\hline Menghayati & & & & \\
\hline Menjelaskan & & & & 4 \\
\hline Mengidentifikasi & & & & \\
\hline Menghafalkan & & & & \\
\hline Mengaitkan & & & & \\
\hline
\end{tabular}


Tabel 7. Kelas XII KMA No. 165 Tahun 2014.

\begin{tabular}{lcccc}
\hline \multirow{2}{*}{ Maharoh MA } & \multicolumn{4}{c}{ KD (Kompetensi Dasar) } \\
\cline { 2 - 5 } & KI 1 & KI 2 & KI 3 & KI 4 \\
\hline Meyakini & 1 & & & \\
Meneladani & & 2 & & \\
Memahami & & & & 2 \\
Menceritkan kembali & & & & \\
Mengambil Ibrah & & & & 5 \\
Mengimplementasikan & 1 & 7 & & \\
Menghayati & 4 & & 18 & \\
Menjelaskan & & & 2 & \\
Mengidentifikasi & & & & \\
Menghafalkan & & & \\
Mengaitkan & & & \\
\hline
\end{tabular}

Pada tabel diatas, dapat diketahui bahwa maharah tingkat SMA dan MA kelas XII menunjukkan kompetensi dasar pada KI 1 lebih menekankan pada kemahiran meyakini dan menghayati. Kompetensi dasar pada KI 2 menekankan pada kemahiran mengimplementasikan. Sedangkan Kompetensi dasar pada KI 3 menekankan pada kemahiran memahami dan menjelaskan. Sedangkan pada kompetensi dasar pada KI 4 menekankan pada kemahiran menjelaskan dan mengimplementasikan. Dari tabel diatas dapat ditarik kesimpulan bahwa ada 4 maharah yang sering muncul dalam kompetensi dasar kelas XII SMA, yaitu maharah meyakini, memahami dan menjelaskan. Adapun dalam koompetensi dasar (KD) kelas XII MA maharah yang sering muncul adalah mengimplemantisakan, menghayati dan menjelaskan.

\section{Analisis Pemetaan Kemahiran Mata Pelajaran SKI jenjang SMA dan MA}

Penyebaran kemahiran yang terdapat dalam penyebaran KD Permendikbud No. 24 Tahun 2016 dan KMA No. 165 Tahun 2014 pada jenjang SMA dan MA sudah menuntut peserta untuk berfikir abstrak. Berdasar analisis terhadap maharah dalam Permendikbud No. 24 Tahun 2016 dan KMA No. 165 Tahun 2014 dari kelas X, XI dan XII dapat disimpulkan bahwa dari 11 maharah yang sering muncul yaitu: meyakini, memahami, mengambil ibrah, mengaitkan, meneladani, mengimplementasikan, menjelaskan, menceritakan kembali, menghayati, menghayati.

Namun dari sebaran kemahiran dalam Permendikbud No. 24 Tahun 2016 dan KMA No. 165 Tahun 2014 jenjang SMA/MA kelas XII juga belum di temukan kemahiran rekonstruksi sejarah. Rekonstruksi sejarah dirasa perlu dimasukkan dalam kemahiran sejarah sebagai suatu acuan dasar dalam mengambil hikmah yang tersimpan di dalam sejarah. Rekontruksi sejarah dibangun dari fakta-fakta sejarah. Dalam rekonstruksi sejarah ini dibangun atas dua proses pengertian yaitu sejarah dalam arti objektif dan sejarah dalam arti subjektif. Rekonstruksi merupakan sebuah upaya penggalian kembali nilai-nilai karakter pada sejarah, dengan mengambil metode berfikir double movement Fadzlur Rahman yaitu menarik nilai ideal moral pada masa lampau, kemudian dirumuskan dan dicari nilai relevansinya di masa sekarang agar dapat memberikan kontribusi terhadap suatu permasalahan. Jika rekonstruksi sejarah ini diterapkan di sekolah, maka ketiga ranah pembelajaran (kognitif, afektif dan psikomotorik) dapat terpenuhi.

Berdasarkan analisis tersebut, peneliti menyimpulkan ada 4 maharah yang harus diajarkan dalam pembelajaran SKI tingkat SMA/MA berdasarkan ranah pengetahuan siswa, yaitu maharah menghayati untuk ranah sikap spiritual, maharah meneladani untuk ranah sikap sosial, merekonstruksi untuk ranah pengetahuan, dan menceritakan kembali untuk ranah keterampilan.

\section{KESIMPULAN}

Menurut hasil analisis pemetaan maharoh mata pelajaran SKI yang berpedoman pada Permendikbud No. 24 Tahun 2016 dan KMA No. 165 Tahun 2014 dapat peneliti simpulkan bahwa kemahiran yang harus dikuasai pada mata pelajaran SKI pada jenjang SMA dan MA adalah maharah menghayati untuk ranah sikap spiritual, maharah meneladani untuk ranah sikap sosial, merekonstruksi untuk ranah pengetahuan, dan menceritakan kembali untuk ranah keterampilan. 
Dari analisis yang ada dapat diketahui bahwa dengan banyaknya maharoh pada tingkatan suatu jenjang tidak menjamin terkuasainya suatu materi, bahkan bisa dengan 2 maharoh saja tetapi materi dapat terkuasai dengan baik dan jelas, sehingga banyak sedikitnya maharoh yang ada pada KD tidak mempengaruhi lengkapnya kemahiran yang dimiliki oleh peserta didik. Saran dari peneliti kepada para pendidik diharapkan agar proses pembelajaran khususnya bidang studi sejarah kebudayaan Islam dapat terkuasai dengan baik dan optimal oleh siswa, maka dapat mengacu beberapa kemaharian yang seharusnya dikuasai oleh siswa jenjang SMA dan MA, selain memperhatikan metode yang tepat dan pas.

\section{DAFTAR PUSTAKA}

Permendikbud No. 24 Tahun 2016

KMA No. 165 Tahun 2014
Departemen Agama RI, Pembelajaran Sejarah Kebudayaan Islam, Jakarta: Direktorat Jenderal Pendidikan Islam, 2009.

M. Basyirudin, Media Pembelajaran, Jakarta: Ciputat Press, 2002.

Imam Barnadib, Filsafat Pendidikan, Yogyakarta: FIP IKIP 1987

Abdurrachman, dkk, Paradigma Pendidikan Islam, Yogyakarta: Pustaka Pelajar, 2001. Ahmad Warson Munawir, Kamus Al Munawir Arab-Indonesia Terlengkap, Surabaya: Pustaka Progresif, 1997.

Acep Hermawan, Metodologi Pembelajaran Bahasa Arab, Bandung: Remaja Rosdakarya, 2011.

Hendri Guntur Tarigan, Membaca Sebagai Suatu Keterampilan Berbahasa, Bandung: Angkasa, 1994. 